ISSN: 0212-0267

DOI: http://dx.doi.org/ro.I420I/hedu2OI534221243

\title{
LA LITERATURA DOCTRINAL Y DEVOCIONAL EN LAS ESCUELAS \\ DEL BARROCO ESPAÑOL. \\ EL MEMENTO MORI COMO MATERIA ESCOLAR
}

\section{Doctrinal and devotional literature in schools of Spanish Baroque. The Memento mori as a school subject}

José Vicente Salido López

Universidad de Castilla La Mancha

Correo-e: JoseVicente.Salido@uclm.es

Recepción: I8 de junio de 20I4. Envío a informantes: 25 de junio de 2014.

Fecha de aceptación definitiva: 26 de marzo de 2015

Resumen: La influencia de la Contrarreforma es fundamental para entender los modelos educativos de finales del siglo xvi y del Barroco. La formación religiosa se convirtió en el principal objetivo de las escuelas de primeras letras, de ahí que los materiales para la lectura y escritura contaran con abundantes textos extraídos de obras doctrinales y devocionales. En el Barroco, por su particular visión de la vida, se enriquecen con reflexiones sobre la muerte y la vanidad mundana. El presente artículo pretende analizar los principales manuales de caligrafía de la época para constatar esta finalidad moralizante en los ejercicios de muestra para alumnos, rastreando las fuentes y el principio pedagógico que subyace en sus autores.

Palabras clave: Contrarreforma; Barroco; Historia de la educación; Caligrafía, Memento mori.

Aвstract: The influence of the Counter-Reformation is fundamental to deal the educational models of the late sixteenth century and Baroque. The religious education became the main focus of the primary schools. It is for that reason that materials for reading and writing include texts from doctrinal and devotional 
works. In the Baroque, because of his particular vision of life, are enriched with reflections on death and worldly vanity. This article aims to analyze the main calligraphy manuals of the period to find this moralizing purpose in exercises for students, tracking the sources and the pedagogical principle followed by their authors.

KEY wORDs: Counter-Reformation; Baroque; History of Education; Calligraphy; Memento mori.

\section{La educación moral y religiosa en la Contrarreforma y el Barroco}

$\mathrm{P}$ ARA ABORDAR LA Historia de la EDUCACión en España es imprescindible contar con el papel fundamental de la Iglesia como integrante activo del sistema de enseñanza en todos sus niveles (Varela, I983). Su labor en este campo, evidentemente, ha tenido un rango secundario, pero ha sido atendida con interés, quizá por su eficacia para el adoctrinamiento y la evangelización. Por eso, no sorprende que en los aproximadamente ciento cincuenta sínodos provinciales que se celebraron entre el Concilio de Letrán (I5I2-I5I7) y el de Trento (I545-I563) se dedicara alguna de sus constituciones a la educación en las parroquias, que fueron núcleos esenciales para la formación en primeras letras, sobre todo en lugares de poca población ${ }^{\mathrm{I}}$. Y esa preocupación se agravó en la etapa postridentina, cuando se genera una cruzada contra la herejía reformista que se sirve de la educación como arma ideológica de primer orden. A partir de aquí, se potencia la fundación y la actividad de esas escuelas parroquiales, que por norma general se encomiendan a sacristanes o a coadjutores, y surge la figura de los visitadores, inspectores de escuela encargados de comprobar la limpieza en los orígenes y los buenos usos de los maestros que ejercían por cuenta propia ${ }^{2}$. Se logra así configurar un modelo muy efectivo para mantener bajo control la enseñanza y a sus agentes; de ahí el interés por conservarlo, a pesar de que los propios maestros organizaron su institución gremial bajo la advocación de san Casiano, que venía a cumplir funciones similares. No es raro documentar aún a la altura del siglo Xvin la existencia de estos sacristanes que ejercían labores docentes en escuelas parroquiales 3 .

García y García, A.: «La Iglesia y la educación. Directrices sinodales (siglos XVII y XVIII)», en Delgado Criado, B. (coord.): Historia de la educación en España y América: La educación en la España Moderna (Siglos XVI-XVIII), Madrid, SM-Morata, 1993, pp. 416-417.

2 Cfr. Bartolomé Martínez, B.: «Las escuelas de primeras letras», en Delgado Criado, B. (coord.): Historia de la educación en España y América. La educación en la España moderna (siglos XVI-XVIII), Madrid, sM-Morata, I993, p. I79; BARTOlomÉ MartíneZ, B.: «Valores pedagógicos de las artes de leer y doctrinas hispanas de los siglos xvir y xviII», en Infantes, V. y Martínez Pereira, A.: De las primeras letras: Cartillas españolas para enseñar a leer del siglo XVII y XVIII, Salamanca, Universidad de Salamanca, 2003, pp. 3I-47; VIÑAO, A.: «La educación institucional. Alfabetización y escolarización», en Delgado CRIAdo, B. (coord.): Historia de la educación en España y América. La educación en la España moderna (siglos XVI-XVIII), Madrid, SM-Morata, I993, pp. I6I-I62; TAPIA, S. de: «La alfabetización de la población urbana castellana en el Siglo de Oro», Historia de la Educación, XII-XIII (I993-94), pp. 277-28I.

3 Cfr. Bartolomé Martínez, B.: «Las escuelas de primeras letras», en Delgado Criado, B. (coord.): Historia de la educación en España y América: La educación en la España Moderna (Siglos XVI-XVIII), Madrid, sM-Morata, I993, p. 500. Ya a finales del siglo XVII, en el sínodo toledano celebrado 

JOSÉ VICENTE SALIDO LÓPEZ

Es cierto que el Concilio de Trento no impuso explícitamente la responsabilidad de la Iglesia sobre el control de la educación, pero los obispos y las órdenes religiosas se sintieron estimulados a contribuir con esa misión educadora mediante la labor de adoctrinamiento y control de los agentes de la educación 4 . Lo que sí se estableció de manera precisa en los estatutos tridentinos fue el desarrollo de la catequesis infantil y su inclusión en la enseñanza de primeras letras. En la sesión XXIV (capítulo IV) sobre la reforma se afirma explícitamente que los obispos «cuidarán [...] de que se enseñe con esmero a los niños, por las personas a quienes pertenezca, en todas las parroquias, por lo menos en los domingos y otros días festivos, los rudimentos de la fe o catecismo, y la obediencia que deben a Dios y a sus padres»'s.

Esta formación catequística no quedó constreñida al ámbito parroquial, sino que recaló también en las escuelas como una tarea más del maestro. De esta manera, la doctrina católica quedó integrada en el plan educativo, no únicamente como materia de enseñanza explícita, a la que se dedicaba normalmente el sábado ${ }^{6}$, sino como material auxiliar para el resto de disciplinas, porque los textos bíblicos, doctrinales y catequéticos eran empleados para el aprendizaje de las reglas gramaticales, para la práctica de la lectura o para ejercicios caligráficos. De ello dan muestra los catones y cartillas de la época, bien nutridos de textos religiosos ${ }^{7}$ y algunos maestros de entonces que han dejado testimonio de su labor:

Y porque nuestro dicípulo no comience a letrear en las quatro oraciones, como ordinariamente se acostumbra, no por esto el que enseña se descuide de hazer que

en 1682 y presidido por el arzobispo Manuel Luis Portocarrero, se insiste en la conveniencia de perpetuar este modelo escolar: «Por tanto, siguiendo la disposición de los Sacros Cánones S.S.A. estatuimos y ordenamos que en cada una de las iglesias parroquiales de nuestro Arçobispado el cura tenga consigo otro clérigo o sacristán, persona de saber y honestidad, que sepa y quiera enseñar a leer, escrivir y contar a qualesquier personas, en especial a los hijos de sus parroquianos, e instruirlos y enseñarles todas las buenas costumbres y apartarlos de cualquier vicio y castigarlos» (Canon, III). No es raro, por tanto, que en el siglo xviII aún se documente la existencia de sacristanes dedicados a la enseñanza de las primeras letras.

4 Cfr. Martín SÁnchez, M. Á.: «Implicaciones educativas de la Reforma y Contrarreforma en la Europa del Renacimiento», Cauriensia, v (2010), pp. 215-236.

"Cfr. Vergara, J.: «La Iglesia y la educación», en Delgado Criado, B. (coord.): Historia de la educación en España y América: La educación en la España Moderna (Siglos XVI-XVIII), Madrid, SM-Morata, 1993, pp. 53-56.

6 Ceballos, B. A. de: Libro histórico y moral sobre el origen y las excelencias del nobilíssimo arte de leer y escrivir y contar y su enseñança, Madrid, Antonio González de Reyes, 1692, pp. I05 y 231; Aznar de Polanco, J. C.: Arte nuevo de escribir por preceptos geométricos y reglas mathemáticas, Madrid, I7I9, f. 48v.; Olod, L. de: Tratado del origen y arte de escribir bien, Gerona, Narciso Oliva, I766, p. 25 .

Para un listado exhaustivo de las cartillas que circulaban en los siglos xv y xvI, véase Infantes, V.: De las primeras letras. Cartillas españolas para enseñar a leer de los siglos XV y XVI, Salamanca, Universidad de Salamanca, 1997; para las publicadas en los siglos Xvir y XVII, INFANTES, V. y Martínez Pereira, A.: «Cartillas y doctrinas del siglo xviI: primer censo bibliográfico», Historia de la Educación, i8 (1999), pp. 335-354, e Infantes, V. y Martínez Pereira, A.: De las primeras letras. Cartillas españolas para enseñar a leer del siglo XVII, 2 vols., Salamanca, Universidad de Salamanca, 2003. La mayoría de los títulos dan cuenta de ese hermanamiento entre aprendizaje de la lectura y doctrina católica. 
las deprenda de coro, a lo menos en romance, con todo lo demás de la doctrina christiana, según se contiene en este tratado, que en latín, quando lo sepa leer, las aprenderá fácilmente y muy bien, que antes con dificultad grande lo hará y jamás dexará de pronunciar mal muchas palabras. Esto digo porque podría dezir alguno que començando a letrear en las quatro oraciones, las aprenderá. Aquí tratamos de enseñarles leer y como son niños no es inconviniente que sea en niñerías, pero tenga tan gran cuenta el que los enseñare de hacerles aprender la doctrina christiana; que el leer y escribir y lo demás, como tengo dicho, que les enseñare tenga por acessorio respeto de lo que toca a buena christiandad, pues esto es lo cierto y lo ques [sic] Dios nos manda ${ }^{8}$.

Se otorgaba, así, en medio del plan formativo, un puesto de privilegio a la educación religiosa, ubicada incluso un escalón por encima del aprendizaje de las destrezas relacionadas con la lectoescritura y con los conocimientos matemáticos básicos. Hasta tal punto se consideraba fundamental el elemento doctrinal dentro de la enseñanza, que era costumbre pensar que la función primordial del educador era formar buenos cristianos, antes que adiestrar en habilidades esenciales para la integración social del individuo como la lectura, la escritura o las matemáticas. Así lo cuenta José de Casanova, calígrafo aragonés que tuvo escuela en Madrid desde i642:

No ay duda sino que es una de las mayores obligaciones la que tienen los maestros de escuela y la más importante y de mayor confiança que ay en la república christiana, pues tienen a su cargo el criar, industriar y enseñar a la juventud en letras y virtud y principalmente en el temor de Dios, Nuestro Señor, que es el principio de toda sabiduria. [...] Lo primero, deven ser los maestros muy temerosos de Dios y muy compuestos delante de sus discípulos en palabras y acciones, dándoles buen exemplo de toda virtud, particularmente frequentando los Santos Sacramentos de la confessión y comunión, para que puedan imitar lo que en ellos vieren. Procurarán imponer a los niños en la virtud, reprehendiendo y castigando con rigor la mala costumbre de jurar y maldezir y palabras deshonestas, dándoles a entender lo que es un pecado mortal y cómo por él queda el alma en desgracia de su Criador y desheredada del Cielo. [...] Serán muy vigilantes en enseñarles todos los días la Doctrina Christiana y particularmente hazer que los sábados traiga cada uno de memoria un capítulo del catecismo con el ayudar a missa, que apremiándolos desta manera en pocos días tomarán de memoria todo el catecismo, haziéndoles que lo buelvan a repetir de nuevo desde su principio, por que no se les olvide. Finalmente, deven exortar a los niños a la guarda de la Ley de Dios, al confessarse y comulgar los que tuvieren edad, a la obediencia de sus padres, a la devoción de oír missa, a la veneración de los templos y sacerdotes, y muy en particular a la devoción al Santíssimo Sacramento del Altar y de la Reina de los Ángeles, Señora Nuestra, concebida sin pecado original, y del Ángel de su guarda, que con esto y su buena industria y cuidado y la intercessión de la Madre de Dios saldrán muy aprovechados sus discípulos y conseguirán el premio de la vida eterna?.

8 Cuesta, J. de: Libro y tratado para enseñar leer y escrevir brevemente, Madrid, Juan Gracián, I584, I, f. $20 \mathrm{~V}$.

9 Casanova, J. de: Primera parte del Arte de escribir todas formas de letras, Madrid, Diego Díaz de la Carrera, i650, vi, f. 5 v. 

JOSÉ VICENTE SALIDO LÓPEZ

Se comprenderá esta obsesión por la cuestión religiosa a poco que se tenga en consideración la esencia de la filosofía contrarreformista que da pie a esta corriente pedagógica y que tiene mucho que ver en la formación de la mentalidad barroca y de su idea de la perfección vital conformada desde la premisa de la religión católica. La vida terrena se concibe como proceso de realización humana inmanente en este mundo, pero dentro de una visión transcendente, contemplada desde la divinidad y sus designios ${ }^{10}$. No hay, por tanto, tarea más importante para el hombre barroco que allanar en la vida el camino hacia una eternidad gozosa ganada con el ejercicio de la virtud; por eso no se olvida desde las primeras letras la atención a los asuntos morales y a la recta religiosidad. A todo ello hay que sumar la idea general que impera en la época de que el paso por la tierra no es más que tránsito, en muchos casos penoso, hacia la vida eterna; de ahí que también se reserve un espacio en el plan formativo del alumno a la muerte y a su preparación, por ser trance inevitable que evalúa las acciones del individuo en la vida y determina su suerte para la eternidad.

\section{La concepción de la muerte en la Contrarreforma y el Barroco}

En medio de esa formación religiosa que copaba la atención del educador, la muerte, como materia inherente a la religiosidad, no era tema tabú; muy al contrario, su presencia es relativamente frecuente en el ámbito educativo para ayudar en la recta formación moral y doctrinal del alumno. Tiene mucho que ver en ello la mentalidad del Barroco y su manera de concebir la muerte como un elemento cotidiano. La alta mortandad y la miseria que se padeció en la época generaron una corriente de pesimismo y de desencanto con la vida y sus engaños que explica en buena medida el origen de esta corriente de pensamiento.

También tuvo que ver en su difusión la labor de la pastoral contrarreformista, que insistió en la constante memoria de la muerte, posiblemente como método amedrentador. Para facilitar su recuerdo, no dudó en utilizar las artes plásticas, el teatro, la letra impresa e incluso ejercicios de imaginación, generalizando así su presencia en múltiples ámbitos de la vida ${ }^{\text {II }}$. Y, desde el púlpito, los predicadores inciden en el recuerdo de la muerte y en su continua reflexión, animando a la meditación sobre las postrimerías, al rechazo de los bienes mundanos y a la preparación durante toda la vida de una muerte santa. Si ya la muerte es motivo de angustia para cualquier cultura, una labor tan intensa de mentalización, unida a la idea de juicio que le acompaña en el cristianismo, explica la obsesión que se tiene por la muerte en el seiscientos y su visión angustiosa ${ }^{12}$.

10 Cfr. Núñez Beltrán, M. Á.: La oratoria sagrada de la época del Barroco. Doctrina, cultura y actitud ante la vida desde los sermones sevillanos del siglo XVII, Sevilla, Universidad de Sevilla, 200o, p. 330 .

II Cfr. Martínez Gil, F.: Muerte y sociedad en la España de los Austrias, Cuenca, Universidad de Castilla-La Mancha, 2000, pp. 322-323.

${ }_{12} C f r$. Núñez Beltrán, M. Á.: La oratoria sagrada de la época del Barroco. Doctrina, cultura y actitud ante la vida desde los sermones sevillanos del siglo XVII, Sevilla, Universidad de Sevilla, 2000, pp. 427-428. 
Suponía esta filosofía vital un curioso contraste con la visión abierta y optimista que se vivió en el Renacimiento, cuando la confianza en el hombre y en sus saberes fue el pilar esencial del humanismo ${ }^{\mathrm{I}}$. Y en lo que a la muerte toca, podría decirse que del Carpe diem se pasó al Memento mori, dos formas radicalmente opuestas de afrontar su presencia inevitable. Si el Carpe diem invitaba al disfrute gozoso de la existencia fundamentándose en su brevedad, por ese mismo argumento el Memento mori anima a una reflexión en tono penitencial sobre la cercanía de la muerte y la conveniencia de una vida virtuosa orientada a su preparación.

La frase latina Memento mori tiene su origen en una advertencia de los siervos a los generales que habían triunfado en la batalla para que no olvidaran su naturaleza humana. La sentencia completa dice:

Memento mori.

Memento te hominem esse.

Respice post te!

Hominem te esse memento! ${ }^{14}$.

Ya en la Edad Media fue reinterpretada en clave cristiana por la orden trapense, que la convirtió en motivo fundamental de su disciplina ${ }^{15}$. El recuerdo de la muerte se convierte en incentivo para soportar una vida de privaciones que busca su recompensa en la eternidad. Y con esa interpretación, normalmente enriquecida con la idea del poder igualatorio de la muerte, se generalizó en el pensamiento bajomedieval. Tras ese breve lapso renacentista que comentábamos unas líneas atrás, que en realidad no fue tan radical como se suele pintar desde la teoría ${ }^{16}$, el Barroco retoma con interés renovado la atención por la muerte. El arte de bien morir se convierte en la «ciencia de las ciencias», en palabras del franciscano fray Juan de Madridi ${ }^{7}$, y así se explica la proliferación editorial de la literatura dedicada al Ars moriendi ya en la segunda mitad del siglo xvi, pero, sobre todo, en el $\mathrm{XVII}^{18}$. Y, junto a estas artes, también se incrementa la publicación de literatura hagiográfica, con modelos sobre enfermedades y muertes santas, devocionarios y

13 Cfr. Rodríguez-San Pedro, L. E.: Lo Barroco: La cultura de un conflicto, Salamanca, I988, pp. 39-47.

${ }_{14}$ Taiano, L.: «Persistencia y desacralización del concepto de Memento mori en la cultura occidental», Isla flotante (2012), p. 80.

is Cfr. KuRTz, J. H.: History of the Christian Church from the Reformation to the Present, vol. III, Whitefish, Kessinger Publishing, 2005, p. I72.

${ }_{16}$ Autores tildados de humanistas como Alfonso Valdés, con su Diálogo de Mercurio y Carón, y otros no tan ligados con las teorías erasmistas, pero que componen en ese ambiente renacentista, como Juan de Pedraza con su Danza de la Muerte, Sebastián de Horozco con su Coloquio de la Muerte con todas las edades y estados, o Luis Hurtado de Toledo, con sus Cortes de la Muerte, afrontan el tema de la muerte y lo hacen con reminiscencias de clara influencia medieval, acudiendo a tópicos como el poder igualatorio de la muerte o la vanidad de los bienes mundanos (RodRíGuezMoranta, I.: «La sátira erasmiana en el Diálogo de Mercurio y Carón de Alfonso Valdés», Lemir, I6 [2012], pp. 349-368).

${ }_{17}$ MADRID, J. de: Milicia sagrada instituyda contra todo el poder del infierno, para socorro de las almas en el artículo de la muerte, Madrid, I697, p. I64.

${ }_{18}$ Cfr. Martínez Gil, F.: Muerte y sociedad en la España de los Austrias, Cuenca, Universidad de Castilla-La Mancha, 2000, pp. 5I-52. 

JOSÉ VICENTE SALIDO LÓPEZ

sermones, y todo tipo de obras doctrinales que se hacen cargo de la importancia de las postrimerías ${ }^{19}$.

Era, en resumen, tarea principal del cristiano del seiscientos preparar la muerte durante toda la vida, por ser desconocido el momento de su llegada pero seguro. Para ello, tiene a su disposición toda esta balumba de instrumentos literarios y artísticos que rescatan buena parte de la tradición medieval sobre la muerte ${ }^{20}$ y que posibilitan que su recuerdo sea una constante en la cotidianidad barroca. Como veremos, ni siquiera a la infancia se la alivia de esa carga, aprovechando en muchas ocasiones las tareas escolares para repetir la idea. La muestra de ello la encontramos en los manuales de caligrafía para uso escolar que se nos han conservado y en los ejercicios que incluían para que los alumnos se soltaran en el arte de escribir. Sus textos, claramente orientados ideológicamente, intentan instruir y educar al tiempo que se practica la escritura, y en esa tarea de doctrina veremos que tampoco se olvida la muerte y su recuerdo ya desde la primera infancia.

\section{El Memento mori en los manuales de caligrafía escolares}

En el año 1548, Juan de Icíar ${ }^{21}$, el famoso calígrafo vizcaíno al que se atribuye el mérito de ser el primero que introdujo la letra bastarda en España, publica su Ortographía práctica (Zaragoza, Bartolomé Nájera). Tras una etapa de formación en Italia, donde conoce la obra de maestros calígrafos de la talla de Tagliente, Pallatino o Cresci, a su llegada a España importa el modelo de trabajo de aquellos con esta obra que buscaba ser manual de escribientes y de maestros de primeras letras. Su estructura, a grandes rasgos, se compone de una primera parte dedicada a los materiales necesarios para la escritura y a las técnicas para su preparación y tratamiento, recomendaciones para el corte y la correcta forma de empuñar la pluma, y una serie de capítulos teóricos sobre las letras más usadas y su trazado. Como muestra de los distintos tipos, con la ayuda de grabadores -muy fructífera en este sentido fue la relación entre Icíar y el grabador Juan de Vingles- ${ }^{22}$ pasaban

19 Cfr. GonzÁlez Lopo, D. L.: «El ritual de la muerte barroca: la hagiografía como paradigma del buen morir cristiano", Semata. Ciencias sociais e bumanidades, I7 (2006), pp. 299-320 y GARCíA FERNÁNDEZ, M.: «"Don Quijote dio su espíritu, quiero decir que se murió”. Claves de la mentalidad tanática barroca castellana», Estudios Humanísticos. Historia, 7 (2008), p. 179.

${ }_{20}$ Cfr. Franco, Á.: «Algunas fuentes medievales del Arte Renacentista y Barroco», Anales de Historia del Arte, Extra I (2008), pp. 73-87.

${ }_{21}$ Para noticias más amplias sobre Juan de Icíar, véase Echegaray, C. de: «Calígrafos vascongados: Juan de Iciar», Revista Internacional de Estudios Vascos, 3 (1907), pp. 242-248 y I-2 (1908), pp. 68-i5o; Cotarelo y Mori, E.: Diccionario biográfico y bibliográfico de calígrafos españoles, 2 vols., Madrid, Revista de Archivos, Bibliotecas y Museos, I9I3 [ed. facs.: Madrid, Visor, 2004], I, pp. 350a-392a; Alonso García, D.: Ioannes de Yciar, calígrafo durangués del siglo XVI, Bilbao, Junta de Cultura de Vizcaya, i953; Vergara, J.: «Juan de Icíar», en Delgado Criado, B. (coord.): Historia de la educación en España y América: La educación en la España Moderna (Siglos XVIXVIII), Madrid, sm-Morata, 1993, pp. I56-I58; Herrera Fernández, E. y Fernández IÑurritegui, L.: «Consideraciones previas para la recuperación y revitalización del legado visual del calígrafo Juan de Ycíar (s. xvi)», Brocar, 32 (2008), pp. 53-64.

22 Sobre la colaboración de Vingles con Icíar, véase, fundamentalmente, Thomas, H.: Juan de Vingles, ilustrador de libros españoles en el siglo XVI, Valencia, Castalia, I949, y Martínez Pereira, 
a letra de molde o tallaban planchas que reproducían ejemplos manuscritos que sirven de modelo para los maestros y de muestra a imitar para el alumnado.

Esta misma estructura sirvió de inspiración para otros calígrafos que, siguiendo el ejemplo de Icíar, se lanzaron a imprimir sus propios tratados de caligrafía ${ }^{23}$. Así, maestros como Francisco Lucas, Ignacio Pérez, Juan de la Cuesta, los Morante o José de Casanova, por citar a los que se ciñen más al modelo, repiten en buena medida la estructura y los contenidos que publica Icíar en esta Ortographía práctica, incluyendo en muchos casos esas muestras manuscritas que daban fe de la maestría de sus autores.

La función pedagógica de estas láminas dentro de los manuales es múltiple: por un lado, ayudaban a aclarar algunas cuestiones técnicas que eran difíciles de explicar sin apoyo visual. La presentación teórica del trazado y características de las letras es, en ocasiones, difícil para los tratadistas, que se ven obligados a incluir ejemplos trazados por su mano para aclarar la explicación. También servían para que el alumno soltara la mano en el ejercicio de la caligrafía, imitando modelos de letras apropiados. Era común, y muchos maestros se quejaban de ello ${ }^{24}$, la picaresca de quienes, sin saber bien el oficio, se dedicaban a enseñar por cuenta propia, transmitiendo a los alumnos vicios en la escritura que luego eran difíciles de erradicar. Estas muestras aseguraban que aquellos maestros que manejaran estos tratados emplearían modelos adecuados si se servían de sus láminas. Por último, tenían funciones formativas y adoctrinadoras, porque los autores aprovechaban la naturaleza repetitiva de estos ejercicios de muestra para incluir textos que delatan una evidente intención educativa y moralizante.

En el contexto educativo de la Contrarreforma, donde prolifera este tipo de manuales, abunda entre los ejercicios de muestra todo tipo de oraciones y textos doctrinales y bíblicos que vienen a cumplir con la que se tenía por principal tarea del maestro: formar buenos cristianos ${ }^{25}$. Se comprueba así ese carácter auxiliar de

A.: «Los manuales de escritura de los Siglos de Oro: problemas bibliográficos», Litterae. Cuadernos sobre Cultura Escrita, 3-4 (2003-4), pp. 138-139, donde se da noticia de bibliografía más amplia sobre el asunto.

${ }_{23}$ Martínez Pereira, A.: «Los manuales de escritura de los Siglos de Oro: problemas bibliográficos», Litterae. Cuadernos sobre Cultura Escrita, 3-4 (2003-4), pp. 135-136.

${ }_{24}$ Alerta Blas Antonio de Ceballos en su Libro de este problema que ocasionaron los llamados licionistas, maestros particulares a domicilio que enseñaban sin un control sobre su dominio de la materia: «Y se devía observar con los licionistas, sujetos no conocidos que se introducen en deslustre del magisterio por su indecente porte, authoridad, respecto y baxo estilo de proceder, en daño de la república en la enseñança de las primeras letras, dando liciones por las casas a particulares, y otros poniendo escuelas públicas por los lugares, sin experiencia, permisso y averiguación de quiénes son, su sabiduría, vida y costumbres, de que resulta gravíssimo perjuizio al próximo, divirtiendo la enseñança y obligando después a los padres gasten de nuevo doblada hazienda y tiempo, que es lo que más importa, para enseñar a sus hijos, y a los discípulos, quando son grandes, a que busquen quien les enseñen a escrivir con propiedad. Y a esto se aplican pocos, y, assí, se quedan con el corriente de una mala forma, por ser difícil de perder la abituación que tienen adquirida» (Libro histórico y moral sobre el origen y las excelencias del nobilíssimo arte de leer y escrivir y contar y su enseñança, Madrid, Antonio González de Reyes, I692, pp. I44-I45).

${ }_{25}$ Quetgles Roca, M. L.: "La educación en el Quijote», Revista de Educación, n. ${ }^{\circ}$ extraordinario (2004), pp. I27-I29. Aunque con el paso del tiempo el componente religioso de estos tratados empieza a debilitarse en beneficio de máximas de autores grecolatinos y mensajes más 

JOSÉ VICENTE SALIDO LÓPEZ

las materias escolares como la lectoescritura con respecto a los contenidos catequéticos al que aludíamos unas líneas atrás. Y, curiosamente, en los manuales compuestos en el contexto barroco tampoco falta la muerte como elemento adoctrinador, según la concepción propia de la época. El Memento mori termina por ser una herramienta pedagógica más para la formación moral e ideológica del alumno.

La Ortographía de Icíar, la que inaugura la tradición impresa de manuales caligráficos en España, es buena muestra de esa función educativa de las láminas de muestra. Se sirvió de textos religiosos y de máximas morales para la confección de las fichas manuscritas, pero ninguna de ellas se dedica a la muerte o a su recuerdo. Quizá a esas alturas la muerte aún no tenía una presencia tan notoria en la cultura y en la sociedad como acabaría teniendo unos años más tarde ${ }^{26}$ o quizá al autor no le pareció un tema apropiado para el público al que se dirigía. Sea lo que fuere, el caso es que tendremos que esperar hasta 1580, fecha en la que se publica la Instrucción muy provechosa para aprender a escrevir (Madrid, Francisco Sánchez), de Francisco Lucas, para encontrar las primeras reflexiones dedicadas a la muerte. A estas alturas, el mensaje de la Contrarreforma ha tenido tiempo de calar y eso, entre otros factores, nos permite entender el interés por la muerte y por su continua preparación.

Lucas incluye en su Instrucción una ficha que reproduce el comienzo del salmo De profundis (f. 28r.). Se trata del salmo I29, uno de los llamados salmos penitenciales, que consiste en un ejercicio de arrepentimiento e imploración de perdón a Dios desde el convencimiento de su infinita misericordia. Se trata de un texto que, aunque no llegue a ser una meditación explícita sobre la muerte, por su tono de contrición se convirtió en una oración frecuente para los momentos de la agonía y del tránsito de la muerte, y así se usó en la liturgia católica. Sabemos, por ejemplo, que fue una lectura a la que recurrió con frecuencia Carlos V en los últimos días de su vida, cuando ya sentía próxima la llegada de la muerte ${ }^{27}$. Y también sabemos por el testimonio que Albert Jouvin dejó en su Viaje de España $y$ Portugal (1672) de su empleo en los ritos funerarios en el siglo Xvir:

Y cuando llevan a alguno a enterrar, lleva el rostro descubierto, teniendo en su mano un cirio en forma de cruz; y si es hombre que no ha dejado medios bastantes, van al borde del camino, y en los cruces donde los sacerdotes se detienen, cantan el «De profundis» y otras oraciones, durante cuyo tiempo van las gentes que piden por las casas con qué enterrarlo y rogar a Dios por él ${ }^{28}$.

relacionados con la virtud moral e intelectual del individuo que con el asunto religioso, todavía en el siglo XviII se percibe ese aire de devocionario en los tratados caligráficos (GARCÍA HuRTAdo, M. R.: «Reflexiones sobre algunos textos destinados a enseñar a leer y escribir en España entre I700 y I780», Obradoiro de Historia Moderna, I3 [2004], pp. IO-II).

${ }_{26}$ En el arte funerario se percibe con nitidez ese cambio de mentalidad ante la muerte a partir de I570, una vez concluido el Concilio de Trento. Las conclusiones que se extraen del ámbito escultórico, donde las alas como símbolo de la rapidez con que llega la muerte y el laurel como signo de su triunfo dejan lugar a las calaveras y a los esqueletos, pueden extrapolarse al contexto literario y educativo (Sebastián, S.: Contrarreforma y Barroco, Madrid, Alianza, 1985, p. 93).

${ }_{27}$ García Fernández, M.: «"Don Quijote dio su espíritu, quiero decir que se murió”. Claves de la mentalidad tanática barroca castellana», Estudios Humanisticos. Historia, 7 (2008), pp. I8I y I87.

${ }_{28}$ García Mercadal, J.: Viajes de extranjeros por España y Portugal, desde los tiempos más remotos hasta principios del siglo XX, 6 vols., Valladolid, I999, III, p. 583. 
No es fácil saber si en el manual tenía una función expresa para la meditación sobre la muerte o no era más que un ejercicio de contrición, pero la connotación fúnebre del salmo, junto con el hecho de que otras láminas sí sean una reflexión evidente sobre la muerte, nos lleva a incluirlo en este catálogo de textos sobre el Memento mori. Que a Lucas le interesaba la reflexión sobre la muerte como ejercicio educativo queda fuera de duda en otra ficha que reproduce con formato de prosa el texto de la quintilla que dice:

Tú, que me miras a mí, tan triste, mortal y feo, mira, pecador de ti, que qual tú te vees, me vi; verte has como me veo ${ }^{29}$.

Se trata de un célebre epitafio que unos años antes de la publicación de la Instrucción de Lucas ya aparecía incluido en el Cancionero de Pedro del Pozo ${ }^{30}$ (Rodríguez-Moñino, 1949-50). Su uso en contextos funerarios lo documenta Caramuel, que lo refiere en su Trimegistus theologicus presentándolo como muy frecuente en los cementerios españoles ${ }^{31}$; y también Jiménez Patón, que en sus Comentarios de erudición nos dice:

Acostumbraban los antiguos a hacer estas memorias, monumentos o sepulcros junto a los caminos para que los muertos que en ellos estaban sepultados avisen a los que pasan cómo ellos fueron hombres y murieron, y que así ellos han de morir y no se engañen juzgándose inmortales, que es lo que ponen sobre algunas calaveras:

Oh, tú que miras a mí

tan triste, mortal y feo,

mira, pecador, por ti,

que cual tú te ves, me vi;

veraste como me veo ${ }^{32}$.

Muestra de la fama de que gozó son las diversas variantes en que se ha conservado en nuestra cultura, llegando a ser casi máxima de nuestra paremiología en su versión más sencilla: «Como te ves, me vi; como me ves, te verás», documentada con relativa frecuencia como epitafio lapidario. Y su eco también llega a la literatura, donde encontramos múltiples alusiones y reminiscencias del poemilla en el Renacimiento y en el Barroco. Lo glosó, por ejemplo, Gregorio Silvestre en su «Texto a una calavera»:

29 Lucas, F.: Arte de escribir. Facsímil de la edición de Madrid, Francisco Sánchez, I580 (BNE R/2753), intr. Ana Martínez Pereira, Madrid, Calambur, 2005, f. 29 r.

30 Rodríguez-Moñino, A.: «El cancionero manuscrito de Pedro del Pozo (I547)», BRAE, XXIX (1949), pp. 453-509, y Xxx (1950), pp. 123-146 y 263-312.

${ }_{31}$ Robledo Estaire, L.: «El cuerpo como discurso: retórica, predicación y comunicación no verbal en Caramuel», Criticón, 84-85 (2002), pp. I50-15I.

32 Jiménez Patón, B.: Comentarios de erudición ( LLibro decimosexto»), ed. M. C. Bosch Juan, J. Garau Amengual, A. Madroñal Durán y J. M. Monterrubio Prieto, Madrid, IberoamericanaVervuert-CSIC, 20IO, p. 266. 
Juventud florida, insana

que a liviandades incita, mira, que es su gloria vana, rocío de la mañana, flor que luego se marchita.

Hombre entre los hombres fui; vesme aquí, en sombras de muerte, y cierto serás así, visto de la misma suerte, tú que me miras a mí.

Cuando en más gloria te vieres, para saber lo que dura, en mí te verás quién eres y en qué paran los placeres de la humana desventura. Y dirasle a tu deseo, si te guía el favor sacro: ya estoy muerto, ya me veo en aqueste simulacro tan triste, mortal y feo.

Y pues se te representa esta muerte sin el cuando para el día de la afrenta, haz cuenta que la estás dando. ¿No ves que estás ciego así, no ves a Dios que te inspira, y te llama para sí?

Abre los ojos y mira, mira, pecador de ti.

Cata que verná a deshora la tragedia del vivir; no te descuides ahora, ensáyate cada hora para que sepas morir. No te ha de valer allí fuerza, valor ni ventura, todo ha pasado por mí; no fíes en hermosura, que cual tú te ves, me vi.

Mírate, parte por parte, $\mathrm{y}$ aprende primero a ver en el libro de humillarte, que de no saber mirarte no te sabes conocer. En el más alto trofeo de los honrosos despojos, 
cuando estés con más arreo, mírate con buenos ojos, y verte has cual yo me veo ${ }^{33}$.

Esta glosa de carácter filosófico-moral, género que se cultivó con relativa frecuencia en la primera mitad del siglo $\mathrm{XVI}^{34}$, condensa a la perfección la manera de entender y afrontar el mundo y sus vanidades, y el conveniente recuerdo de la muerte que fue propio de la Contrarreforma, quizá más en la línea del Tempus fugit que del Memento mori, pero con inevitables puntos de encuentro con la filosofía del Barroco.

Y la prueba irrefutable de su éxito nos la aporta la versión satírica que incluye Quevedo en las Epistolas del Caballero de la Tenaza, en el consejo sobre «qué ha de hacer todo caballero para salvar su dinero a la hora de la daca»:

Al irse a acostar, antes de dormir, se llegará al talegón vacío que tendrá colgado a la cabecera de su cama por calavera de los perdidos, con rótulo que diga:

Tú, que me miras a mí

tan triste, mortal y feo, mira, talegón, por ti, que como te ves me vi, y veraste cual me veo.

Es la misma versión que va a reutilizar en El niño y Peralvillo de Madrid3s, señal de su eficacia como recurso humorístico. Y si fue así, el efecto cómico del contrafactum solo es entendible si se supone la familiaridad de los lectores con el texto que está en el origen, ya que, de no conocerse la copla que motiva el poemilla satírico, se perdería buena parte de su comicidad.

Por último, también hay reminiscencias de la coplilla en La niña de Gómez Arias, de Calderón, ya sin tono burlesco, pero lejos del sentido fúnebre que tuvo en origen:

\footnotetext{
Huye el verte en el estado, tú, en que me miras a mí.

No es buen modo, es desvarío

hacer tan a costa agena

las finezas, que la pena

de otro es escarmiento mío.

¿Cómo dará mi albedrío

licencias a mi deseo

cuando el desengaño veo

hoy de una acción tan horrible,

de un delito tan terrible

tan triste, mortal y feo?
}

33 Silvestre, G.: Poesías, ed. A. Marín Ocete, Granada, Publicaciones de la Facultad de Letras, I938, pp. II2-II3.

${ }_{34}$ Cfr. Rodado, A.: «Literatura manchega hacia I500. La glosa del Cartujano en su contexto», Cuadernos de Estudios Manchegos, 22 (1996), p. I55.

${ }_{35}$ Quevedo, F. de: Obras completas, 2 vols., ed. F. Buendía, Madrid, Aguilar, I974 ${ }^{6}$, I, 86 y II, 568 , respectivamente. 
Si es su ruina en ensayo

de cuerdos avisos lleno, y si me ha avisado el trueno, ¿por qué he de esperar el rayo?

Si a ese pálido desmayo ceniza de amor oí, decirme: ¿engañada fui de un falso amante traidor, cuando con padre y honor como tú te ves me vi?

Creerle quiero y su castigo sea tu misma locura que a mí nadie me asegura de que si ahora te digo, no harás lo mismo conmigo.

Pues mi libertad poseo, huiré tu tirano empleo, que si hasta aquí pude oír, no ha de acabar de decir:

«Veraste como me veo» ${ }^{36}$.

Todo ello es muestra del notable éxito que tuvo la copla como cantar popular, posiblemente motivado por esa moda de utilizarlo como epitafio. Y aunque en su uso vemos que hay quien la desliga de ese contexto funerario, es razonable pensar que el maestro en la escuela orientara su aplicación didáctica a la reflexión sobre la muerte, que es el ámbito que le corresponde por su origen y por el que les sería familiar a los estudiantes.

Tal aplicación no extraña porque Lucas fue un convencido de los beneficios del recuerdo de la muerte para mover al ejercicio de la virtud. Lo deja claro en otra de las fichas que incluye en su manual, la que reza: «La memoria y el pensamiento de la muerte haze apartar al hombre de muchos vicios y emplearse continuamente en exercicios virtuosos ${ }^{37}$. El recuerdo de la muerte, por tanto, formaba parte de sus estrategias educativas y estas muestras manuscritas eran la herramienta idónea para obligar al alumno, a base de la repetición del ejercicio, a la meditación, voluntaria o involuntaria, sobre la muerte.

De 1599 es el Arte de escrevir, de Ignacio Pérez, calígrafo que ejerció la enseñanza de primeras letras con escuela propia en Madrid. Su papel en la historia del magisterio elemental fue básico, porque participó en la formación de la Hermandad de san Casiano y de su Tribunal de Examinadores, que controló el acceso al cuerpo de maestros de primeras letras. También su obra fue referencia entre los calígrafos de la época. La distribuye en ocho capítulos en los que retoma buena parte de los contenidos de la obra de Icíar, explicando los tipos de letra y su trazado, el corte y agarre de la pluma, la fabricación y conservación de la tinta y el empleo de las guías para calcar una serie de láminas manuscritas que compone de su mano.

36 Ochoa, E.: Teatro escogido de Calderón de la Barca, París, Librería Europea de Baudry, I838, p. 683 a.

${ }_{37}$ Lucas, F.: Arte de escribir. Facsímil de la edición de Madrid, Francisco Sánchez, I580 (BNE $R / 2753$ ), intr. Ana Martínez Pereira, Madrid, Calambur, 2005, f. 59r. 
Como en el caso de sus predecesores, esas láminas sirven de instrumento para la formación moral y doctrinal del alumno y, como ya ocurría en la Instrucción de Lucas, el Memento mori vuelve a aparecer como herramienta pedagógica dentro de la escuela. «La continua memoria de la muerte aprovecha mucho al siervo de Dios», dice en un momento de su obra ${ }^{38}$, de ahí que la reflexión sobre el mundo y sus vanidades sea tópico recurrente en esos ejercicios de muestra que cierran su tratado. En uno de ellos vuelve a acudir al libro de los Salmos $(73,20)$, como también hiciera Lucas, en busca de textos para la meditación:

Como sueño de los que se levantan en la ciudad de dormir, así convertirás en nada su imagen, dize a Dios el Psalmista hablando de los mundanos. Sueña el dormido vanidades y, en despertando, conoce ser nada su sueño. Durmieron -dize David- los varones de la riqueza ${ }^{39}$.

La cita no es directa; procede del Libro de la vanidad del mundo, del franciscano Diego de Estella (segunda parte, c. 47), un tratado filosófico que desde el título da pistas de la línea de pensamiento en la que se encuadra. Es reflexión sobre la brevedad de la vida, lo fútil de sus bienes y la trascendencia de la preparación de una muerte santa como paso crucial a la vida eterna. Su empleo en el Arte de Pérez es significativo de las tendencias pedagógicas del autor, sobre todo porque no se trata de un caso aislado. Vuelve a recurrir al tratado de Estella para confeccionar una lámina que contiene un fragmento del capítulo 67 de la segunda parte con cita a los Salmos (35, I2):

Pagávanme males por bienes y esterilidad a mi ánima, dize el Psalmista. Vida es miserable y triste servir a mundo tan ingrato y desconocido. Fiera y perversa condición escoger la mentira y dexar la verdad y querer más los bienes momentáneos transitorios que los eternos perdurables, por aparentes bienes da el mundo pena eterna $a^{40}$.

Y esta otra, extraída del capítulo 39 de esa segunda parte, con cita a la Primera Carta del Apóstol san Juan (2, 15). La vanidad de la vida terrena vuelve a ser motivo central:

«No quieras amar al mundo ni a sus cosas», dize S. Juan. El que no conosce la maldad de una cosa, tanto con más seguridad vive quanto menos se recela del daño que le puede venir junto. Por esso es justo que sepas la condición del mundo, porque, conociéndole, con mayor cautela te guardes. Manifiestos son sus daños y sus costumbres están diciendo lo poco que debe ser amado. Nunca hizo sino engañar a los que a este entregaron fácilmente ${ }^{41}$.

${ }_{38}$ PÉrez, I.: Arte de escrevir con cierta industria e invención para hazer buena forma de letra y aprenderlo con facilidad, Madrid, Imprenta Real [Ed. facs. C. Crespo Tobarra, Madrid, BNE, I992], f. $44 \mathrm{r}$.
39 Ibid., f. $22 \mathrm{r}$.
$4^{\circ} \quad$ Ibid., f. 23 r.
${ }_{41}$ Ibid., f. 26 r. 
Otro de los autores preferidos por Pérez para este tipo de temática es fray Luis de Granada, moralista de los más utilizados en el ámbito escolar, a juzgar por la frecuencia con la que aparecen sus escritos en los manuales de caligrafía y cartillas de lectura. En este caso, la fuente es la Meditación sobre las postrimerías repartidas por siete días de la semana, un conjunto de oraciones para la reflexión sobre la muerte al comienzo y al final de cada día de la semana. De la meditación del viernes por la mañana, que trata «De las penas del infierno» ${ }^{42}$, procede el texto de esta lámina:

Dos géneros de penas ay en el infierno que contienen en sí innumerables números de tormentos ${ }^{43}$.

De la meditación «De las miserias de la vida humana», reservadas para el martes $^{44}$, procede el fragmento de esta otra ficha, dedicada a la fragilidad de la vida humana:

Considera también quán frágil y quebradiza es la vida de los hombres. No ay vidrio en el mundo ni vaso de barro más quebradizo que un cuerpo humano, pues un aire, un sol, le despoja de la vida. Ó, quán bien dixo el profeta estas palabras maravillosas. Toda carne es heno y su gloria es como la flor del campots.

Y «De las honras de los bienaventurados», reservada para el sábado, extrae el texto de esta otra lámina ${ }^{46}$, dedicada a la felicidad eterna en contraposición a las miserias de la vida terrena:

La segunda excelencia de la gloria es la compañía de los bienaventurados. Si acá en el mundo la compañía y conversación de los buenos causa alegría, ¿qué será tratar y conversar en la tierra de amor y paz con tanto número de escogidos todos aunados en caridad? Allí la gloria del uno es la gloria del otro y como san Gregorio dize, esta herencia celestial para todos es una y para cada uno toda porque como está perfecta la caridad cada bienaventurado recibirá tanta alegría de la gloria del otro como si él mismo fuera ${ }^{47}$.

42 Palafox y Mendoza, J. de: Bocados espirituales, políticos, místicos y morales, catecismo y axiomas doctrinales para labradores y gente senzilla, especialmente con otros tratados, Madrid, María de Quiñones, 1662, p. 316.

${ }_{43}$ PÉReZ, I.: Arte de escrevir con cierta industria e invención para hazer buena forma de letra y aprenderlo con facilidad, Madrid, Imprenta Real [Ed. facs. C. Crespo Tobarra, Madrid, BNE, 1992], f. 33r.

${ }^{4}$ Palafox y Mendoza, J. De: Bocados espirituales, políticos, misticos y morales, catecismo y axiomas doctrinales para labradores y gente senzilla, especialmente con otros tratados, Madrid, María de Quiñones, 1662, p. 296.

${ }_{45}$ PÉREZ, I.: Arte de escrevir con cierta industria e invención para hazer buena forma de letra y aprenderlo con facilidad, Madrid, Imprenta Real [Ed. facs. C. Crespo Tobarra, Madrid, BNE, 1992], f. $39 \mathrm{r}$.

${ }_{46}$ Palafox y Mendoza, J. de: Bocados espirituales, políticos, místicos y morales, catecismo y axiomas doctrinales para labradores y gente senzilla, especialmente con otros tratados, Madrid, María de Quiñones, 1662, p. 325.

47 PÉRez, I.: Arte de escrevir con cierta industria e invención para hazer buena forma de letra y aprenderlo con facilidad, Madrid, Imprenta Real [Ed. facs. C. Crespo Tobarra, Madrid, BNE, 1992], f. 4 or. 
En resumen, en el Arte de Pérez el tratamiento de la muerte ya tiene los aires propios del Barroco, con la continua reflexión sobre lo vano de la vida terrenal, con la visión pesimista y trágica de la muerte, y la insistencia en su continuo recuerdo como prevención para el cristiano. De la Primera carta a los Tesalonicenses $(5,2)$ extrae la idea de la siguiente lámina que es buen resumen de esta filosofía:

La muerte es la primera puerta por donde començamos a entrar en las postrimerías y fines del hombre. Por tanto, mira, christiano, que es certísima y que su ora es fortísima. Por tanto la compara el Señor al ladrón de noche que ha de venir en la ora que no pensaremos y cogernos descuidados ${ }^{48}$.

Ya dentro del siglo Xvir, encontramos esta misma corriente pedagógica en el manual de otro de los grandes de la caligrafía española, Pedro Díaz Morante, que en I6r6 publica su Nueva arte de escrevir (Madrid, Luis Sánchez). Conoció esta obra otras tres partes más, publicadas en 1624 (Segunda parte del Arte de escrivir, Madrid, Luis Sánchez), en I629 (Tercera parte del Arte nueva de escrivir, Madrid, Imprenta Real) y en I63I (Quarta parte del Arte nueva de escrivir, Madrid, Juan González), esta última con la colaboración de su hijo homónimo para la confección de alguna de las fichas manuscritas. Morante no fue un calígrafo al uso; la destreza con la pluma que demuestra en las orlas de trazo continuo con las que adorna sus fichas le merece el título de artista. Sus mejoras en la técnica del ligado de letras que Lucas había ideado unos años antes lo colocan en la vanguardia de la didáctica de las primeras letras, logrando verdaderos avances en los resultados y en los tiempos de aprendizaje. Y el mensaje moralizante que transmite en buena parte de las fichas que compone denota la intención pedagógica que es deje de su profesión como maestro de primeras letras. En suma, fue artista, investigador y pedagogo, canalizando todas esas facetas a través de su pasión por la caligrafía.

Nos interesa ahora su vertiente pedagógica y sus ideas sobre la educación, que, como veremos, siguen la línea que predomina desde la Contrarreforma. Aunque sus escritos no son tratados de pedagogía al uso, en sus láminas de muestra da las claves de su filosofía educativa. Su intención moralizante y adoctrinadora queda patente en un buen número de ellas, en las que vuelve a acudir, como ya había hecho Lucas, a diversos textos doctrinales y religiosos entre los que no faltan alusiones a la muerte y a su recuerdo como herramienta educativa. Continúa, por tanto, esa línea pedagógica que encuentra en la muerte el elemento amedrentador para convencer de la conveniencia de una vida recta en lo moral. Hay una muestra de letra redonda en la Segunda parte que es muy ilustrativa al respecto:

Alma mía, coraçón mío, ¿cómo as sido ingrato a tu amantíssimo Dios? Buelve y rebuelve sobre ti, confiesa tu culpa y tus muchos y graves pecados, haz penitencia $\mathrm{y}$ vive en justicia y verdad. Advierte que no tienes ora segura ${ }^{49}$.

${ }^{48} \quad$ Ibid., f. 25r.

49 Díaz Morante, P.: Segunda parte del Arte de escrivir, Madrid, Luis Sánchez, I624. 

JOSÉ VICENTE SALIDO LÓPEZ

Contrición y temor a Dios son los pilares que deben sustentar la formación moral del individuo, según Morante, y la motivación para no relajarse en su práctica es el incierto momento de la muerte. Volvemos a la muerte y a su recuerdo como un elemento más del plan formativo. Como complemento, en varios momentos acude al tópico del Tempus fugit, pero con un carácter mucho más sombrío que el que tenía en el Renacimiento, porque subyace debajo ese recuerdo temeroso de la muerte tan propio del Barroco. Su presencia y la amenaza del infierno condicionan esa percepción de la fugacidad del tiempo, transformando lo que en el Renacimiento era vitalidad, en angustiosa espera y meditación. Lo vemos en la ficha de la Segunda parte que contiene las dos primeras estrofas de las Coplas de Manrique, en la de la Tercera parte, incluida por partida doble, en la que con unos artísticos peces forma el texto que dice «Breve vida» o en esta elocuente muestra de la Quarta parte que condensa en unas pocas líneas la esencia de esta reflexión sobre la muerte:

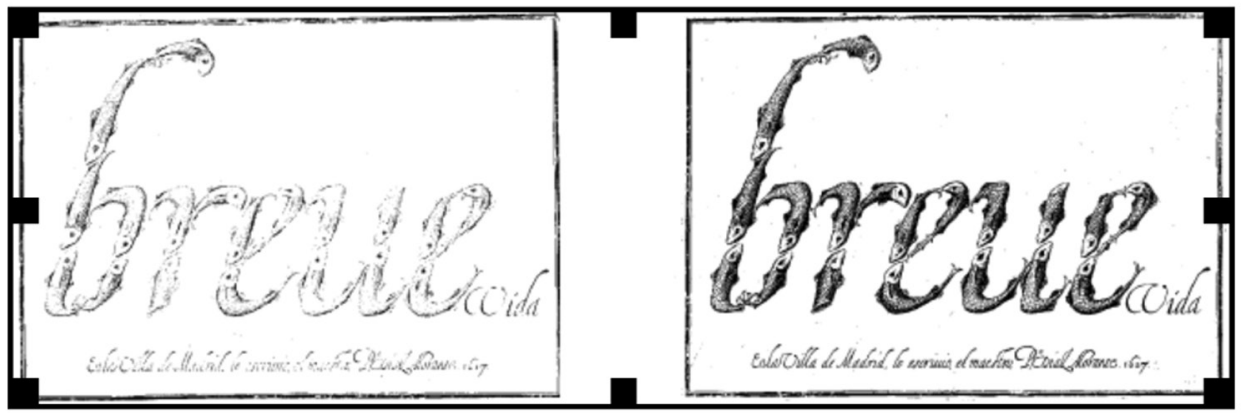

Ilustraciones extraídas del ejemplar U/10413 de la BNE.

¡Ó, qué poco! ¡Ó, qué mucho! Momento y eternidad. ¡Ó, qué poco! ¡Ó, qué mucho! ¿Quién lo supiera pensar? ¡Ó qué poco es lo que dura esta vida y sus contentos! $¡ O$, qué mucho los tormentos del infierno! ${ }^{\circ}$.

El tono delata la influencia de las artes moriendi y las reflexiones sobre las postrimerías que tanto éxito editorial tuvieron en el Barroco. De hecho, esa relación entre los conceptos antagónicos momento y eternidad es un recurso frecuente en este tipo de tratados, que se refieren a la muerte como el Momentum a quo (pendet) aeternitas ${ }^{\mathrm{s}}$, o incluso a la vida en su conjunto ${ }^{5_{2}}$. Pero, además de

so Díaz Morante, P.: Quarta parte del Arte nueva de escrivir, Madrid, Juan Gonçález, I63I.

sI Cfr. Roca y Serna, A. de la: Luz del alma para la hora de la muerte, S. 1., s. n., s. a., p. 245; Boyenval, A. de: Amaritudo dulcissima sive de bono mortis et praeparatione ad momentum a quo pendet aeternitas, Paris, Iacobo Dugast, i638; García Megía, A. y Mira y Gómez de Mercado, M. D. (eds.): Juan Falconi: 1596-I638. Antología de textos, Almería, Universidad de Almería, 2008, p. Io6; Feijoo, B. J.: Cartas eruditas y curiosas, Madrid, Pedro Marín, I774, IV, p. 2; Salazar, F. de: Afectos y consideraciones devotas y eficaces añadidas a los exercicios de nuestro P.S. Ignacio de Loyola, fundador de la Compañia de Jesús, Madrid, Imprenta de Aguado, I832, v, p. 4.

${ }_{52}$ Ribot y de Alegre, J.: Camino a la perfección christiana por el medio de las más importantes máximas de virtud y santos documentos sacados de los exercicios espirituales de los Santos Padres, Barcelona, María Martí, I724, IX, p. I2. 
por esas reminiscencias, el fragmento es especialmente ilustrativo para lo que nos interesa ahora porque el texto forma parte de un famoso milagro atribuido al carmelita Francisco Yepes, realizado para animar a la meditación sobre la muerte y la eternidad. Así lo relata Boneta en sus Gritos del Infierno:

Apareciose Christo al venerable Yepes y le dixo encargasse a su confessor que a todos los penitentes de qualquiera estado les enseñasse a tener oración mental. Y para que ninguno se escusasse, les diera este método fácil de que enfrente de la pieza en que de ordinario están, pongan una $O$ grande y otra $o$ pequeña para que en la $O$ grande meditasen la eternidad de la otra vida y en la pequeña la brevedad desta, diziendo entre sí quando la vean: ¡Ó, qué poco! ¡Ó, qué mucho! ¡Qué poco lo de acá! ¡Qué mucho lo de allá! Lo qual será al justo consuelo, porque conocerá quán poco es lo que aquí ha de padecer y quán mucho lo que allí ha de gozar, y será despertador al mundano, porque exclamará: ¡Ó, qué poco me han de durar estas vanidades! ¡Ó, qué mucho he de padecer por ellas! Y como los hombres -le dixo Christo- hagan esto, yo les ayudaré para que internamente se recojan y vivan y mueran bien. A los que no, les haré cargo en el juizio de que no lo hizieron y para su mayor tormento tendrán siempre delante las dos letras en el Infierno, a cuya vista clamarán: $¡$ Ó, qué poco fue lo que gozamos! ¡Ó, qué mucho y que insufrible es, y qué interminable lo que padecemos aquí!s’.

El milagro, publicado por primera vez en la Vida y virtudes del venerable Francisco Yepes, de José de Velasco ${ }^{54}$, tuvo una enorme difusión en la época, a la que posiblemente colaborara este empleo que se le dio en contextos escolares. No sería extraño que este ejercicio de muestra fuera el complemento caligráfico de una lección más amplia que presentara y reflexionara sobre el milagro de Yepes, los beneficios de la oración mental y demás enseñanzas doctrinales que se extraen del fragmento. Así, el ejercicio caligráfico se convierte en reflexión y meditación para interiorizar el mensaje moral que contiene el texto transcrito.

También es interesante un fragmento que Morante toma de los Pastores de Belén, de Lope de Vega, incluido en la Quarta parte. Sin duda, fue un gesto de agradecimiento del calígrafo a Lope, con el que debió de mantener una cordial, cercana y continuada relación. Así se desprende de la reiterada colaboración del Fénix con Morante, al que dedica elogiosos versos que se incluyen en los preliminares de las distintas ediciones del Arte. Morante posiblemente quisiera devolver la fineza dedicando una de sus fichas a la transcripción de alguna composición de Lope, y de entre su vastísima producción, la elección fue esta:

Si el que da la vida llora, ¿cómo se puede reír el triste que á de morir? Entró la muerte en la tierra por el pecado del hombre. Bajó Dios, tomó su nombre y en paz se trocó la guerra. Tan frío portal le encierra, que queda llorando agora. Pues, ¿cómo, aunque se mejora, se alegra de aquesta suerte el que dio causa a la muerte si el que da la vida llora? Bien es tener alegría de nuestro bien y salud,

53 BonetA, J.: Gritos del Infierno para dispertar al mundo, Figueras, Ignacio Poster, s. a., I, 5, 2.

54 Velasco, J. de: Vida y virtudes del venerable varón Francisco de Yepes, Valladolid, Jerónimo Murillo, I6I7, I, I3. 

JOSÉ VICENTE SALIDO LÓPEZ

pues de este niño en virtud comiença desde este día. Pero templarse devría con ver lo que á de sufrir, que de nacer a morir él mismo llora también, porque mirando por quién, ¿cómo se puede reír?ss.

Se trata de una glosa de un cantar popular que Lope de Vega pone en boca del pastor Fabio, uno de los que en la ficción había participado en la Adoración y había compuesto esta glosa. La canción se completa con esta estrofa: «Si a los tesoros mortales, / que solo aparentes son, / tiene el hombre inclinación / y deja los celestiales, / tenga sus bienes por males; / porque si piensa reír / lo que es tan justo sentir, / arguyo de su placer / que no debe de saber / el triste que ha de morir» ${ }^{56}$. Resulta, cuando menos, curioso que Morante se fijara, de entre la inmensidad de textos lopescos, precisamente en este. El hecho es significativo de la intención de Morante, que educa con el convencimiento de que el arte de bien morir es la «ciencia de las ciencias»:

Dize el glorioso san Gregorio que aquel vive bien que aprende y estudia cómo á de morir, y el que no sabe esto, no sabe nada ni le son de provecho las ciencias que sabe. ¿Qué le aprovechó a Aristóteles todo quanto estudió y todo quanto supo? Nada. Assí lo confessó estando cercano a la muerte, quando, rogándole sus discípulos les dixese alguna sentencia notable, pues tantas avía dicho y escripto en vida, respondió esta: «Entré con pobreza en este mundo, viví con misseria, muero con ignorancia de lo que me importava saber». Y dixo bien, porque no avía estudiado cómo avía de morir. Muchos discípulos tiene Aristóteles de las ciencias que supo y muchos le siguen en sus opiniones, pero muchos más le siguen en sus ignorancias, pues no aprendió ni supo cómo avía de morir bien, porque unos gastan el tiempo en estudiar gramática y saber muchas congruencias y composición de palabras y en las suyas no la tienen, sino mentiras y lisonjas ${ }^{57}$.

La cita a san Gregorio Magno procede del libro i2 de sus Morales, un comentario al Libro de Job. Era un texto de relativa recurrencia en este tipo de literatura sobre la vanitas mundana, muy adecuado al pensamiento barroco y a su característica inseguridad; lo refiere, por ejemplo, Juan Eusebio Nieremberg en el De la diferencia entre lo temporal y eterno, y crisol de desengaños ${ }^{5}$, o Antonio de Alvarado en el Arte de bien morir's9, la que posiblemente fuera la fuente que empleó Morante. Transcribe literalmente este fragmento y continúa la cita ${ }^{60}$ en otra lámina manuscrita incluida en la Quarta parte, señal de su interés por recalcar -curiosamente en un contexto educativo- la preponderancia de la preparación de la muerte sobre el dominio de los saberes científicos:

" Díaz Morante, P.: Quarta parte del Arte nueva de escrivir, Madrid, Juan Gonçález, I63I.

56 Vega, L. de: Pastores de Belén, prosas y versos divinos de Lope de Vega Carpio, ed. E. Suárez Figaredo, 20II, pp. 315-316 [En línea]. http://users.ipfw.edu/jehle/CERVANTE/othertxts/Suarez Figaredo_PastoresDeBelen.pdf (Consulta: O2/12/2013).

57 Díaz Morante, P.: Tercera parte del Arte nueva de escrivir, Madrid, Imprenta Real, I629.

58 Nieremberg, J. E.: De la diferencia entre lo temporal y lo eterno, BAE, t. civ, Madrid, Atlas, I957, II, 3,3 .

59 Alvarado, A. de: Arte de bien morir, Navarra, Nicolás de Assiaín, I615, I, I, 6-7.

60 Ibid., I, I, 7-9. 
Unos gastan el tiempo en estudiar Gramática y saber mucha congruencia y composición de palabras y en las suyas no la tienen, sino que con mentiras, mormuraciones, lisonjas y juramentos cometen mil barbarismos. Otros se precian de grandes rethóricos para mover humanos afectos y olvídanse de que la muerte es cierta. Otros procuran saber medir el cielo y la tierra por sus proporciones mathemáticas y no se acuerdan de medir por la consideración siete pies della para su sepultura. Otros saben por la Arizmética mucho de qüenta y no saben tenerla de su vida ni contar sus breves días, ni qual será el de la muerte. Otros se ocupan en saber la armonía y consonancia de voces y fuera mejor atender a remediar las disonancias de sus costumbres. Otros... ${ }^{\text {r. }}$.

Ya hacia mediados del siglo xviI, José de Casanova, maestro aragonés que desde 1642 ejercía con escuela propia en Madrid, publica su Primera parte del arte de escrivir todas formas de letras ${ }^{62}$. Es otro de los manuales que fue tomado como referencia por los tratadistas y calígrafos de los siglos Xvir y xviII, que le otorgan a su autor título de autoridad en la materia. Es un tratado que tiene un componente más erudito que los publicados hasta entonces, pero conserva las cuestiones estrictamente técnicas, incluyendo un apartado con láminas de muestra con distintos tipos de letras. Para su composición acude a textos doctrinales y moralizantes que extrae de fuentes como el Memorial de la vida christiana o la Meditación de la Sagrada Pasión, de fray Luis de Granada; la Guirnalda mística, de Baltasar Boch Centellas y Cardona; el Vetus disciplina canonicorum, de Eusebio Amort; o los Quinientos proverbios de consejos y avisos por manera de letania, de Luis de Escobar, entre otros. La temática de las láminas es diversa, abordando nuevamente el tema de la muerte. En una de sus láminas incluye una fórmula piadosa, similar a otras incluidas en devocionarios como el Manual de piadosas meditaciones o los Exercicios espirituales de Antonio de Molina (I693), que incide en los beneficios del recuerdo de la muerte como acicate para la penitencia:

Hombre miserable, considera continuamente que vas caminando a la sepultura y que la muerte es vigilante. Mira que a muchos les quitó repentinamente la vida. No te fíes en mañana; haz penitencia juntando lágrimas con arrepentimiento verdadero de tus pecados ${ }^{63}$.

El Memento mori sirve, una vez más, de herramienta para disponer al cristiano contra el pecado y mantenerlo alerta para evitar la condenación eterna a los tormentos del infierno. Tomar conciencia del continuo acecho de la muerte para alejar de las malas costumbres ya desde la primera infancia es un recurso que emplea Casanova en su tratado -y es de suponer que también en su escuela- con asiduidad. Veamos un ejemplo más:

Primeramente, hombre christiano, deves con atención considerar que no conviene dilatar, como dilatas, la enmienda de tu vida de día en día, de semana en semana, de mes en mes y de año en año. Es muy tardía la penitencia hecha mañana.

Díaz Morante, P.: Quarta parte del Arte nueva de escrivir, Madrid, Juan Gonçález, I6zI.

62 Madrid, Diego Díaz de la Carrera, I650.

${ }_{63}$ Ibid., f. 22 r. 

JOSÉ VICENTE SALIDO LÓPEZ

Comiénçala oy, considerando que eres como una candela encendida que por instantes se va consumiendo y acavando, y que no sabes si mañana te dará la muerte tiempo para arrepentirte de tus pecados. No ay precio ninguno para comprar el tiempo perdido, por más diamantes que des por él, ni avrá mercader que te lo venda en su tienda. Las piedras preciosas son paja en comparación del tiempo que corre. Considera también que estás cargado de innumerables deudas. Piensa enteramente tus pecados, tantos lascivos pensamientos, tantas palabras no solamente ociosas, sino afrentosas y maldicientes. Mira estos montones de culpas, que es fuerça que las confieses. Considera, assimismo, diligentemente quánto dieran los condenados por una ora de tiempo de tantas como tú desperdicias en vanaglorias y entretenimientos con liberalíssima pereza de la enmienda. Considera juntamente que eres sueño y que muchos se pusieron a dormir que murieron repentinamente. Morir tenemos; fuerça es caminar y pasar al otro mundo. Y de la misma manera que tiene Dios numerados tus cabellos, tiene contados tus más mínimos pensamientos para darte luego immediatamente el premio o castigo; ambos son para una eternidad. Acuérdate de la muerte ${ }^{64}$.

Retoma en este ejercicio toda una suerte de tópicos sobre el paso del tiempo y la muerte que encuentran amplio eco en la cultura del Barroco ${ }^{65}$. Pero, sin duda, el más interesante para lo que nos ocupa es el que relaciona el sueño con la muerte, porque pone en relación directa el texto con las artes moriendi. Fue un ejercicio recurrente en obras dedicadas a la preparación del último trance el de animar al que medita a reflexionar antes de ir a dormir, aprovechando la similitud entre el sueño y la muerte ${ }^{66}$. El final del día se planteaba como momento idóneo para el examen de conciencia, en una especie de ensayo de las postrimerías. El mensaje es similar al que aparece en la traducción que fray Luis de Granada, uno de los autores más relacionados con la meditación de la muerte ${ }^{67}$ y de los más utilizados por Casanova, incluye en su traducción del Contemptus mundi, de Tomás de Kempis:

Bienaventurado el que tiene siempre la hora de su muerte ante sus ojos y se apareja cada día a morir. Si viste morir algún hombre, piensa que por aquella carrera has de pasar. Cuando fuere de mañana, piensa que no llegarás a la noche. Y cuando noche, no te oses prometer de ver la mañana; porque muchos mueren súbitamente. Por eso vive siempre aparejado y con tanta vigilancia, que nunca la muerte te halle desapercibido ${ }^{68}$.

Precisamente del Memorial de la vida cristiana, de Luis de Granada, procede el texto de esta otra ficha manuscrita. Se incluye en el capítulo titulado «De las

${ }^{64}$ Ibid., f. 28 r.

65 Cfr. Martínez Gil, F.: Muerte y sociedad en la España de los Austrias, Cuenca, Universidad de Castilla-La Mancha, 200o, pp. 344-346.

${ }_{66}$ Jerónimo Gracián en su Arte de bien morir, Juan de Ávila en varios textos de su producción o Francisco de Arana en su Muerte preparada recomiendan este tipo de ejercicio de meditación sobre la muerte. Fueron muchos más, algunos ciertamente originales, los métodos que los tratadistas proponían para quienes se aproximaban a este tipo de reflexión. Para un análisis más detallado sobre la cuestión, véase el capítulo que dedica al memento mori MARTínez GiL (2000: 343-349).

${ }_{67}$ Cfr. Sebastián, S.: Contrarreforma y Barroco, Madrid, Alianza, 1985, p. 94.

68 Kempis, T. de: Contemptus mundi o menosprecio del mundo y imitación de Cristo, trad. Fray Luis de Granada, Madrid, BAE, I906, t. XI, p. 389. 
penas del Infierno» ${ }^{69}$, una fuente cuando menos curiosa para acudir en busca de modelos de muestras para la enseñanza de primeras letras:

Por lo mismo has de considerar que, después que sea pronunciada la sentencia por aquel Supremo Juez, irán los bienaventurados a gozar de su gloriosa presencia y los condenados al fuego eterno. Imagina que es el infierno un lago profundísimo lleno de llamas, cuyos moradores están continuamente despedaçándose con alaridos por los dolorosos tormentos que padecen. Mira quán grandíssimo tormento será estar las desdichadas almas quemándose perpetuamente sin acabarse de consumir o atormentar. Pues si esto es assí, dime, hombre desatinado, si tener la mano sobre una brasa de lumbre por espacio de un credo te parece intolerable tormento, y no avría cosa en el mundo que no hicieses por escusarlo, ¿cómo no haces algo por no estar en aquella cama infernal eternamente ${ }^{70}$.

\section{Conclusiones}

La educación de la primera infancia en la Contrarreforma y el Barroco cuenta con un alto contenido doctrinal que es el resultado de la reacción de Trento contra los postulados protestantes. La escuela se concibe entonces como centro esencial para el control ideológico del individuo, y al maestro, como agente activo del proceso de educación, se le asignan funciones que rebasan los límites estrictamente formativos para entrar en el ámbito del adoctrinamiento. Los textos escolares, que se componen esencialmente de cartillas, catones y christus, dan cuenta de ese interés primordial en la formación religiosa según las enseñanzas apostólicas y romanas; los delata el empleo reiterado de oraciones y de textos hagiográficos y de devoción que sirven de base para el ejercicio de la lectura, aprovechando la ocasión para dejar una enseñanza moralizante. Y de igual manera se aprovecha el ejercicio de la escritura para aproximar al niño a la doctrina con textos de muestra que presentan una manifiesta orientación ideológica.

Por tanto, aunque en la cultura contrarreformista la catequesis se vincula fundamentalmente con lo oral, recurriendo en muchos casos a la memorización y a la recitación colectiva para su aprendizaje, no es cierto que el aprendizaje catequético estuviera totalmente desvinculado de la lectura y la escritura ${ }^{71}$. En la práctica escolar se aprovecha cualquier actividad para la enseñanza de la doctrina religiosa, incluidas las que tienen que ver con la lengua escrita.

Pero lo verdaderamente llamativo es que en el contexto del Barroco esa enseñanza religiosa se complementa con la meditación sobre la muerte como motivo pedagógico ya desde la escuela de primeras letras. Por entonces, autores como fray Luis de Granada, Antonio de Alvarado, Tomás de Kempis o Juan Eusebio de

69 IV, 4, I7.

70 Casanova, J. de: Primera parte del Arte de escribir todas formas de letras, Madrid, Diego Díaz de la Carrera, I650, vi, f. 26r.

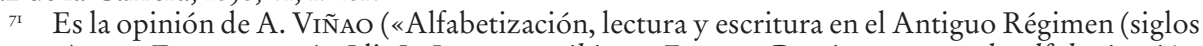
XVI-XviII)», en Escolano, A. [dir.]: Leer y escribir en España. Doscientos años de alfabetización, Madrid, Fundación Germán Sánchez Ruipérez, I992, p. 5I). 
Nieremberg, los grandes tratadistas sobre las postrimerías, irrumpen con fuerza en los manuales escolares de lectura y escritura, y sus enseñanzas son utilizadas como herramienta amedrentadora para la recta formación de los discentes.

Evidentemente, mucho tiene que ver este fenómeno con la peculiar percepción de la muerte en el Barroco y con el halo macabro que la envuelve. Quienes se han ocupado del asunto han encontrado las causas de este aspecto de la mentalidad barroca en la alta mortandad de la época y en la intensa labor doctrinal de la Contrarreforma, pero la intervención escolar en esta línea, ampliamente documentada en estos ejercicios de caligrafía, sin duda debió de mover los ánimos con mucha más eficacia. Sabían bien los educadores que «los niños son cera que recibe la forma que le dan $»^{72}$; que al niño del Barroco se le recuerde casi a diario que la muerte está acechando es razón más que válida para explicar el pensamiento de la época en relación a la vida y a sus vanidades.

72 Bonifacio, J.: Christiani pueri institutio, apud VARela, J.: Modos de educación en la España de la contrarreforma, Madrid, La Piqueta. Varela, 1983, p. 31. 